\title{
Calculations Predict That Carbon Tunneling Allows the Degenerate Cope Rearrangement of Semibullvalene to Occur Rapidly at Cryogenic Temperatures
}

2010

Vol. 12, No. 12

2798-2801

\section{Xue Zhang, David A. Hrovat, and Weston Thatcher Borden* \\ Department of Chemistry and Center for Advanced Scientific Computing and \\ Modeling, University of North Texas, 1155 Union Circle \#305070, \\ Denton, Texas 76203-5017}

borden@unt.edu

Received April 17, 2010

\section{ABSTRACT}

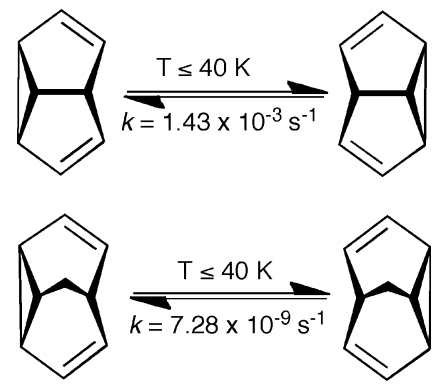

Calculations on the role of tunneling in the degenerate Cope rearrangements of semibullvalene (1) and barbaralane (3) predict that, at temperatures below $40 \mathrm{~K}$, tunneling from the lowest vibrational level should make the temperature-independent rate constants $k=1.43 \times 10^{-3} \mathrm{~s}^{-1}$ and $k=7.28 \times 10^{-9} \mathrm{~s}^{-1}$, respectively. An experiment, using semibullvalene-2(4)- $d_{1}$, is proposed to test the prediction of rapid tunneling by 1 at cryogenic temperatures.

Tunneling in chemical reactions by hydrogen and its isotopes is relatively common, on account of their low masses. ${ }^{1}$ In contrast, reactions involving tunneling by heavier atoms, such as carbon, are comparatively rare. ${ }^{1 \mathrm{~b}}$ Reactions in which there is strong evidence for tunneling by carbon include the ring closure reactions of cyclopentane-1,3-diyl ${ }^{2}$ and cyclobutane1,3 -diyl, ${ }^{3}$ the automerization of cyclobutadiene, ${ }^{4}$ and the ring

(1) Reviews: (a) Bell, R. P. The Tunneling Effect in Chemistry; Chapman and Hall: London and New York, 1980. (b) Sheridan, R. S. In Reviews in Reactive Intermediate Chemistry; Moss, R. A., Platz, M. S., Jones, M. J., Jr., Eds.; John Wiley \& Sons: New York, 2007; p 415. (c) Hynes, J. T.; Klinman, J. P.; Limbach, H.-H.; Schowen, R. L. Hydrogen Transfer Reactions; Wiley-VCH: Weinheim, Germany, 2007; Vols. 1-4.

(2) (a) Buckwalter, S.; Closs, G. J. Am. Chem. Soc. 1975, 97, 3587. (b) Buckwalter, S.; Closs, G. J. Am. Chem. Soc. 1979, 101, 4688. expansions of 1-methylcyclobutylfluorocarbene ${ }^{5}$ and noradamantylchlorocarbene. ${ }^{6}$ Experimental evidence, which supports the prediction that tunneling should play an important role in the ring-opening reaction of cyclopropylcarbinyl

(3) Sponsler, M.; Jain, R.; Coms, F.; Dougherty, D. A.; Buckwalter, S.; Closs, G. J. Am. Chem. Soc. 1989, 111, 2240.

(4) (a) Carpenter, B. K. J. Am. Chem. Soc. 1983, 105, 1700. (b) Huang, M. J.; Wolfsberg, M. J. Am. Chem. Soc. 1984, 106, 4039. (c) Dewar, M. J. S.; Merz, K. M., Jr.; Stewart, J. J. P. J. Am. Chem. Soc. 1984, 106, 4040. (d) Lefebvre, R.; Moiseyev, N. J. Am. Chem. Soc. 1990, 112, 5052. (e) Arnold, B. R.; Michl, J. In Spectroscopy of Carbenes and Biradicals; Platz, M. S., Ed.; Plenum Press: New York, 1990; p 1. (f) Redington, R. L. J. Chem. Phys. 1998, 109, 10781.

(5) Zuev, P. S.; Sheridan, R. S.; Albu, T. V.; Truhlar, D. G.; Hrovat, D. A.; Borden, W. T. Science 2003, 299, 5608.

(6) Moss, R. A.; Sauers, R. R.; Sheridan, R. S.; Zuev, P. S. J. Am. Chem. Soc. 2004, 126, 10196. 
radical at low temperatures, ${ }^{7}$ has very recently been obtained by James and Singleton. ${ }^{8}$

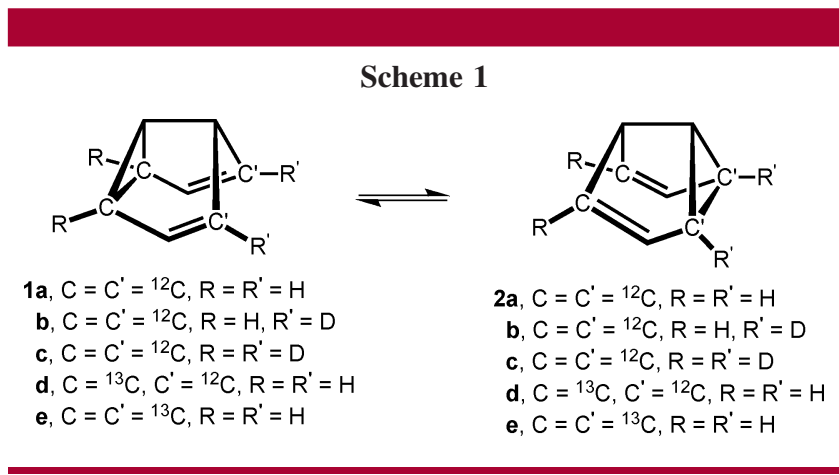

In this communication, we report the results of calculations that predict tunneling by carbon should allow the Cope rearrangement of semibullvalene $(\mathbf{1}$, Scheme 1$)$ to occur rapidly at cryogenic temperatures. We also propose a possible way to test this prediction experimentally.

Since the first synthesis of $\mathbf{1 a}$ by Zimmerman et al., ${ }^{9}$ more than four decades ago, semibullvalene has fascinated chemists because it undergoes a degenerate boat Cope rearrangement with an enthalpic barrier of only $\Delta H^{\ddagger}=5.0 \pm 0.2$ $\mathrm{kcal} / \mathrm{mol} .^{10,11}$ The low barrier height is one reason why $\mathbf{1}$ might be a good candidate for undergoing this reaction rapidly at cryogenic temperatures by tunneling. ${ }^{1}$

However, even more important than the low barrier height for facilitating tunneling in the degenerate rearrangement of $\mathbf{1}$ is the narrowness of the reaction barrier. ${ }^{1-7}$ In breaking the cyclopropane ring bond, the distance between the carbons that form this bond increases by only about $0.86 \AA \AA^{12}$ On the other hand, in forming the same type of bond at the other end of the molecule, the distance between another pair of carbons must decrease by this amount. Therefore, as in the case of the automerization of cyclobutadiene, ${ }^{4}$ two pairs of carbons must move, in order for the degenerate Cope rearrangement of $\mathbf{1}$ to occur. Consequently, in both reactions, either the effective tunneling mass is $2 \times 12=24$ (or 26, if the hydrogens attached to the carbons are included) or, equivalently, the effective width of the barrier through which

(7) (a) Datta, A.; Hrovat, D. A.; Borden, W. T. J. Am. Chem. Soc. 2008 , 130, 6684. (b) Zhang, X.; Datta, A.; Hrovat, D. A.; Borden, W. T. J. Am. Chem. Soc. 2009, 131, 16002.

(8) James, O. G.; Singleton, D. A.; Zhang, X.; Hrovat, D. A.; Borden, W. T., manuscript in preparation.

(9) (a) Zimmerman, H. E.; Grunewald, G. L. J. Am. Chem. Soc. 1966 88, 183. (b) Zimmerman, H. E.; Binkley, R. W.; Givens, R. S.; Grunewald, G. L.; Sherwin, M. A. J. Am. Chem. Soc. 1969, 91, 3316.

(10) (a) Cheng, A. K.; Anet, F. A. L.; Mioduski, J.; Meinwald, J. J. Am. Chem. Soc. 1974, 96, 2887. (b) Moskau, D.; Aydin, R.; Leber, W.; Gunther, H.; Quast, H.; Martin, H.-D.; Hassenruck, K.; Miller, L. S.; Grohmann, K Chem. Ber. 1989, 122, 925.

(11) Reviews: (a) Williams, R. V. Chem. Rev. 2001, 101, 1185. (b) Williams, R. V. Adv. Theor. Interesting Mol. 1998, 4, 157. (c) Williams, R. V. Eur. J. Org. Chem. 2001, 227. (d) Childs, R. F.; Cremer, D.; Elia, G. In The Chemistry of the Cyclopropyl Group ; Rappoport, Z., Ed.; J. Wiley \& Sons: Chichester, 1995; Vol. 2, p 411.

(12) Jiao, H.; Nagelkerke, R.; Kurtz, H. A.; Williams, R. V.; Borden, W. T.; Schleyer, P. v. R. J. Am. Chem. Soc. 1997, 119, 5921. tunneling occurs is a factor of $\sqrt{ } 2$ larger than the tunneling distance for just one pair of carbons. ${ }^{13}$

To carry out tunneling calculations on the degenerate Cope rearrangement of $\mathbf{1}$, we performed electronic structure calculations on this reaction with the B3LYP functional ${ }^{14}$ and the $6-31 \mathrm{G}(\mathrm{d})$ basis set. ${ }^{15}$ It was already known that the B3LYP/6-31G(d) enthalpy of activation of $\Delta H^{\ddagger}=4.5 \mathrm{kcal} /$ $\mathrm{mol}^{12}$ is in good agreement with the experimental values of $\Delta H^{\ddagger}=5.0 \pm 0.2 \mathrm{kcal} / \mathrm{mol} .{ }^{10}$ Quantum effects on the reaction dynamics were computed semiclassically, using the smallcurvature tunneling (SCT) approximation. ${ }^{16}$ The direct dynamics calculations were carried out with GAUSSRATE ${ }^{17}$ as the interface between Gaussian $03^{18}$ and POLYRATE. ${ }^{19}$

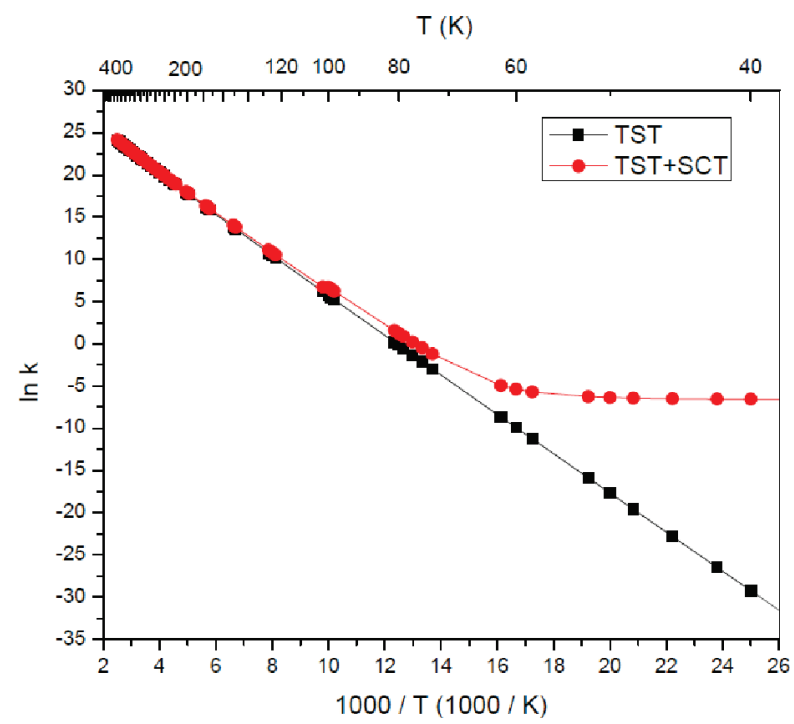

Figure 1. Arrhenius plot of the TST and TST + SCT rate constants for the Cope rearrangement of semibullvalene from 40 to $400 \mathrm{~K}$.

Our results are displayed graphically in the Arrhenius plots shown in Figure 1. The points on the black line were computed using conventional transition state theory (TST), ${ }^{20}$

(13) The imaginary frequency that is associated with tunneling through a parabolic reaction barrier is inversely proportional to both the width of the barrier and the square root of the effective mass. Therefore, either increasing the barrier width by $\sqrt{ } 2$ or doubling the effective mass decreases the imaginary frequency by a factor of $\sqrt{ } 2$. Hence, either change has the same effect on reducing the probability of tunneling. (See ref 1a).

(14) (a) Becke, A. D. J. Chem. Phys. 1993, 98, 5648. (b) Lee, C.; Yang, W.; Parr, R. G. Phys. Rev. B 1988, 37, 78. (c) Miehlich, B.; Savin, A.; Stoll, H.; Preuss, H. Chem. Phys. Lett. 1989, 157, 200.

(15) Hariharan, P. C.; Pople, J. A. Theor. Chim. Acta 1973, 28, 213.

(16) Fernandez-Ramos, A.; Ellingson, B. A.; Garrett, B. C.; Truhlar, D. G. In Reviews in Computational Chemistry, 23; Lipkowitz, K. B., Cundari, T. R., Eds.; Wiley-VCH: Hoboken, NJ, 2007; pp 125-232.

(17) Corchado, J. C.; Chuang, Y.-Y.; Coitino, E. L.; Truhlar, D. G. GAUSSRATE-version 9.5; University of Minnesota: Minneapolis, MN, 2007.

(18) Frisch, M. J. et al. Gaussian 03, revision D.02; Gaussian, Inc.: Wallingford, CT, 2004. The full reference is given in the Supporting Information.

(19) Corchado, J. C. et al. POLYRATE-version 9.5; University of Minnesota: Minneapolis, MN, 2007. The full reference is given in the Supporting Information. 
and the points on the red line were computed by TST, with inclusion of SCT.

At temperatures down to $100 \mathrm{~K}$, the two types of calculations can be seen to provide almost identical results. For example, at $100 \mathrm{~K}, k(\mathrm{TST}+\mathrm{SCT})=5.48 \times 10^{2} \mathrm{~s}^{-1}$, which is only a factor of 1.8 larger than $k$ (TST). At $100 \mathrm{~K}$, the calculated activation parameters are also almost the same $-E_{\mathrm{a}}=4.43 \mathrm{kcal} / \mathrm{mol}$ and $\log A=12.37 \mathrm{~s}^{-1}$ with inclusion of tunneling, and $E_{\mathrm{a}}=4.71 \mathrm{kcal} / \mathrm{mol}$ and $\log A=$ $12.72 \mathrm{~s}^{-1}$ without it. Tunneling increases the reaction rate by lowering the average energy at which molecules can react. However, as shown by the relative sizes of the $A$ factors, the probability of tunneling through the barrier is lower than the probability of passing over it. ${ }^{21}$

As can be seen in Figure 1, below $100 \mathrm{~K}$ the curvature in the TST + SCT Arrhenius plot becomes obvious. As the temperature is decreased below $100 \mathrm{~K}$, not only do more molecules react by tunneling but also more molecules tunnel from the lowest vibrational level of the reactant. Below 40 $\mathrm{K}, k(\mathrm{TST}+\mathrm{SCT})$ becomes essentially temperature independent (i.e., $E_{\mathrm{a}}=0$ ), as all the reacting molecules tunnel from the lowest vibrational energy level.

At $40 \mathrm{~K}, k(\mathrm{TST}+\mathrm{SCT})=1.43 \times 10^{-3} \mathrm{~s}^{-1}$; so from this temperature down to $0 \mathrm{~K}$, the half-time for the degenerate rearrangement of semibullvalene is calculated to be $485 \mathrm{~s}$ $\approx 8 \mathrm{~min}$. Without tunneling, TST predicts that at $40 \mathrm{~K}$ the half time for reaction would be a factor of $10^{10}$ longer.

We also have carried out TST + SCT calculations on the degenerate Cope rearrangement of barbaralane $(3) .{ }^{22}$ The value of $\Delta H^{\ddagger}=7.3 \mathrm{kcal} / \mathrm{mol}$, which has been measured for this reaction, ${ }^{23}$ is $2.3 \mathrm{kcal} / \mathrm{mol}$ higher than the value of $\Delta H^{\ddagger}$ $=5.0 \pm 0.2 \mathrm{kcal} / \mathrm{mol}$, which has measured for degenerate rearrangement of $\mathbf{1}$ at somewhat lower temperatures. ${ }^{10}$ In good agreement with experiment, B3LYP/6-31G(d) calculations, without any tunneling corrections, give $1.9 \mathrm{kcal} / \mathrm{mol}$ for the difference in $\Delta H^{\ddagger}$ values. ${ }^{24}$

B3LYP/6-31G(d) calculations also find that, on breaking the cyclopropane ring bond in the degenerate rearrangement of 3 , the change in $\mathrm{C}-\mathrm{C}$ distance of $0.82 \AA$ is $0.07 \AA$ larger than the change of $0.75 \AA$ in the degenerate rearrangement of $\mathbf{1} .^{25}$ This result suggests that the barrier to degenerate rearrangement is not only higher but also wider in $\mathbf{3}$ than in 1. Consequently, tunneling through the barrier should be slower for $\mathbf{3}$ than for $\mathbf{1}^{1}$

Indeed, at $40 \mathrm{~K}$, the rate constant for tunneling in the degenerate rearrangement of $\mathbf{3}$ (Scheme 2) is computed to

(20) Although we usually use canonical variational transition state theory (CVT) to locate transition states for tunneling calculations, ${ }^{7}$ in the degenerate rearrangement of semibullvalene, the location of the transition state along the reaction coordinate is determined by symmetry, so CVT calculations are unnecessary.

(21) However, quantum mechanical reflection of molecules from the top of the barrier makes the TST + SCT rate constant for passage over the reaction barrier slightly smaller than the TST rate constant.

(22) Doering, W. von E.; Ferrier, B. M.; Fossel, E. T.; Hartenstein, J. H.; Jones, M., Jr.; Klumpp, G.; Rubin, R. M.; Saunders, M. Tetrahedron 1967, 23, 3943.

(23) (a) Günther, H.; Runsink, J.; Schmickler, H.; Schmitt, P. J. Org. Chem. 1985, 50, 289. (b) Jackman, L. M.; Fernandes, E.; Heubes, M.; Quast, H. Eur. J. Org. Chem. 1998, 2209.

(24) Hrovat, D. A.; Brown, E. C.; Williams, R. V.; Quast, H.; Borden, W. T. J. Org. Chem. 2005, 70, 2627.
Scheme 2

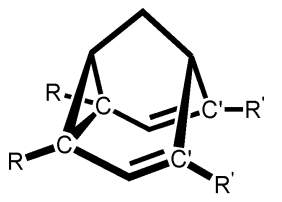

3

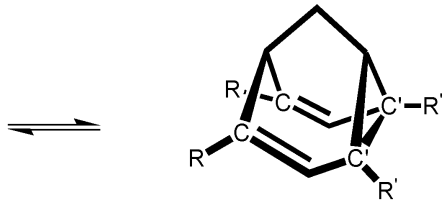

4 be $k(\mathrm{TST}+\mathrm{SCT})=7.28 \times 10^{-9} \mathrm{~s}^{-1}$. This rate constant is $5.09 \times 10^{-5}$ smaller than the rate constant for tunneling in the degenerate rearrangement of 1 . At $40 \mathrm{~K}$, the half time for rearrangement is computed to be 8.7 years for $\mathbf{3}$, compared to about $8 \mathrm{~min}$ for 1 . Thus, our calculations predict that the slightly higher and wider barrier for degenerate rearrangement of $\mathbf{3}$ than for $\mathbf{1}^{24}$ should make the rate of degenerate rearrangement of $\mathbf{3}$ at $40 \mathrm{~K}$ too slow to measure, whereas the rate of degenerate rearrangement of $\mathbf{1}$ at $40 \mathrm{~K}$ by tunneling is predicted to be fast enough to be easily measurable.

The rate of degenerate rearrangement of $\mathbf{1 a}$ can be obtained by NMR line-shape analysis at temperatures above $100 \mathrm{~K}$, but below $100 \mathrm{~K}$, the rate of this reaction is computed to be too slow to affect the NMR spectrum of 1a. ${ }^{10}$ Isotopic labeling, as in $\mathbf{1 b}$ or $\mathbf{1 d}$, might provide a way to follow the rates of their Cope rearrangements at $40 \mathrm{~K}$, but it would be important first to know how large the kinetic effects of isotopic substitution in 1a are likely to be. Therefore, we carried out calculations on the effects of isotopic substitution on the rate of Cope rearrangement of $\mathbf{1}$ at $40 \mathrm{~K}$.

Table 1. TST + SCT KIEs Calculated for Cope Rearrangement of 1 at $40 \mathrm{~K}$

\begin{tabular}{lccc}
\hline reactants & $k\left({ }^{12} \mathrm{CH} /{ }^{12} \mathrm{CD}\right)$ & $k\left({ }^{12} \mathrm{CH} /{ }^{13} \mathrm{CH}\right)$ & $k\left({ }^{12} \mathrm{CD} /{ }^{13} \mathrm{CH}\right)$ \\
\hline 1b and 1d & 0.73 & 2.41 & 3.29 \\
1c and 1e & 2.03 & 5.65 & 2.78 \\
\hline
\end{tabular}

Some $\mathrm{H} / \mathrm{D}$ and ${ }^{12} \mathrm{C} /{ }^{13} \mathrm{C}$ kinetic isotope effects (KIEs) on the Cope rearrangement of $\mathbf{1}$, calculated by TST + SCT at $40 \mathrm{~K}$, are given in Table 1. Calculations at lower temperatures give essentially the same results because, again, below $40 \mathrm{~K}$ all of the reaction occurs by tunneling from the lowest vibrational level of not only $\mathbf{1}$ but also of its isotopomers.

As would be expected, substitution of ${ }^{13} \mathrm{C}$ for ${ }^{12} \mathrm{C}$ at the terminal atoms of $\mathbf{1}$ is predicted to slow the rate of tunneling. The KIE for substitution of ${ }^{13} \mathrm{C}$ for ${ }^{12} \mathrm{C}$ at all four terminal carbons, as in 1e, is almost exactly the square of the KIE for substitution of ${ }^{13} \mathrm{C}$ for ${ }^{12} \mathrm{C}$ at just one end of $\mathbf{1}$, as in $\mathbf{1 d}$.

Although the KIE for substitution of $\mathrm{D}$ for $\mathrm{H}$ at all four terminal carbons (as in 1c) is also computed to be normal, ${ }^{26}$ the KIE for substitution of $\mathrm{D}$ for $\mathrm{H}$ at just one end of $\mathbf{1}$ (as in 1b) is calculated to be inverse. In other words, despite the greater mass of two deuteria, compared to two hydrogens, 
1b is predicted to tunnel faster than $\mathbf{1 a}$ by a factor of $1 / 0.73$ $=1.37$. This is, to the best of our knowledge, only the second prediction of a large inverse KIE on the rate of a tunneling reaction. ${ }^{27}$

The inverse KIE, predicted for substitution of deuteria for hydrogens in $\mathbf{1 b}$, but not in $\mathbf{1 c}$, is readily explicable. Replacement of $\mathrm{H}$ by $\mathrm{D}$ is computed to make the Cope rearrangement of $\mathbf{1 b}$ to $\mathbf{2 b}$ exothermic by $0.17 \mathrm{kcal} / \mathrm{mol}$ at $40 \mathrm{~K}$. As is usually the case for equilibrium isotope effects, the higher $\mathrm{C}-\mathrm{H}$ bending frequency at carbons that are nominally $\mathrm{sp}^{3}$, rather than $\mathrm{sp}^{2}$, makes the zero-point energy lower in $\mathbf{2 b}$ than in $\mathbf{1} \mathbf{b}{ }^{28}$

The exothermicity of the conversion of $\mathbf{1 b}$ to $\mathbf{2} \mathbf{b}$ is calculated not only to make the effective barrier height to Cope rearrangement lower in $\mathbf{1 b}$ than in $\mathbf{1 a}$ by about 0.04 $\mathrm{kcal} / \mathrm{mol}$ at $40 \mathrm{~K}$ but also to narrow the barrier. The lowering and narrowing of the barrier, through which tunneling must occur, is calculated to make the rate of tunneling faster in 1b than in $\mathbf{1 a}$ by a factor of 1.37 below $40 \mathrm{~K}$, despite the larger effective tunneling mass in $\mathbf{1} \mathbf{b}$.

Of course, the free energy change for rearrangement of $1 \mathbf{c}$ to $\mathbf{2 c}$, like that for the rearrangement of $1 \mathbf{a}$ to $\mathbf{2 a}$, is zero. Therefore, the only difference between the degenerate rearrangements of $\mathbf{1 a}$ and $\mathbf{1} \mathbf{c}$ is the greater effective tunneling mass in the rearrangement of $\mathbf{1 c}$. As shown in Table 1, this

(25) The actual barrier width for degenerate rearrangement from the lowest vibrational state is computed to be $0.62 \AA$ for $\mathbf{1}$ and $0.72 \AA$ for 3.

(26) Normal KIEs for passage of 1c and 1e over the reaction barrier are calculated by TST. The possibility of inverse KIEs on the passage of 1c and 1e over the reaction barrier has been discussed by: Bergman, K.; Görtler, S.; Manz, J.; Quast, H. J. Am. Chem. Soc. 1993, 115, 1490.

(27) See ref $7 \mathrm{~b}$ for the first example. There have been some other tunneling reactions for which inverse KIEs have been predicted, but the size of the predicted KIEs has been very small: (a) Alhambra, C.; Gao, J. L.; Corchado, J. C.; Villa, J.; Truhlar, D. G. J. Am. Chem. Soc. 1999 121, 2253. (b) Truong, T. N.; McCammon, J. A. J. Am. Chem. Soc. 1991, 113, 7504. (c) Corchado, J. C.; Espinosa-Garcia, J. J. Chem. Phys. 1996, 105, 3160. (d) Villa, J.; Gonzalez-Lafont, A.; Lluch, J. M. J. Phys. Chem. 1996, 100, 19389. (e) Hu, W.-P.; Rossi, I.; Corchado, J. C.; Truhlar, D. G. J. Phys. Chem. A 1997, 101, 6911.

(28) Streitwieser, A., Jr.; Jagow, R. H.; Fahey, R. C.; Suzuki, S. J. Am. Chem. Soc. 1958, 80, 2326.

(29) This proposed experiment has much in common with the method used to measure the rates of conversion of the twist-boat to the chair conformation of cyclohexane ( Squillacote, M.; Sheridan, R. S.; Chapman, O. L.; Anet, F. A. L. J. Am. Chem. Soc. 1975, 97, 3244)and of s-cis- to s-trans-butadiene (Squillacote, M. E.; Sheridan, R. S.; Chapman, O. L.; Anet, F. A. L. J. Am. Chem. Soc. 1979, 101, 3675).

(30) Askani, R.; Kalinowski, H.-O.; Weuste, B. Org. Mag. Res. 1982, 18, 176. Askani's experiments found that the enthalpic preference for deuterium to be attached to the cyclopropane ring in 1,5-dimethylsemibullvalene-2(4)- $d_{1}$ amounts to $\Delta H=0.11 \mathrm{kcal} / \mathrm{mol}$, which is in reasonable agreement with our calculated value of $\Delta H=0.09 \mathrm{kcal} / \mathrm{mol}$ for semibullvalene without the two methyl groups.

(31) After completion of this research, we learned from Professor Barry Carpenter that he had previously considered and sought experimental evidence for tunneling by carbon in the degenerate rearrangement of semibullvalene. Lyons, B. A. Ph.D. thesis, Cornell University, 1989. difference is computed to result in a normal KIE of $k(\mathbf{1 a}) /$ $k(\mathbf{1 c})=2.03$.

Although ${ }^{13} \mathrm{CH}$ and ${ }^{12} \mathrm{CD}$ have the same mass, Table 1 shows that the isotopic substitution of ${ }^{13} \mathrm{C}$ for ${ }^{12} \mathrm{C}$ in $1 \mathrm{e}$ is computed to produce a 2.78 times larger KIE on tunneling than substitution of $\mathrm{H}$ for $\mathrm{D}$ in 1c. In the cleavage of the $\mathrm{C}^{2}-\mathrm{C}^{8}$ bond and the forming of the $\mathrm{C}^{4}-\mathrm{C}^{6}$ bond of $\mathbf{1}$, the carbons are computed to move about $0.19 \AA$ more than the hydrogens attached to them. Therefore, the isotopic substitution of $\mathrm{C}^{13}$ for $\mathrm{C}^{12}$ as in 1e would, indeed, be expected to have a larger effect than the isotopic substitution of $\mathrm{D}$ for $\mathrm{H}$ as in 1c, on retarding the rate of tunneling by increasing the effective mass that tunnels.

It might be possible to measure the rate of rearrangement of $\mathbf{1 b}$ to $\mathbf{2 b}$ at cryogenic temperatures by taking advantage of the fact that this reaction is nondegenerate and has $\Delta G \approx$ $-0.17 \mathrm{kcal} / \mathrm{mol}$ at both high and low temperatures. At 298 $\mathrm{K}$, this small free energy difference corresponds to an equilibrium constant for formation of $\mathbf{2 b}$ from $\mathbf{1 b}$ of only $K$ $=1.25$. However, this equilibrium constant increases to $K$ $=8.48$ at $40 \mathrm{~K}$ and to $K=5260$ at $10 \mathrm{~K}$. Therefore, if the 5:4 equilibrium mixture of $\mathbf{2} \mathbf{b}$ to $\mathbf{1 b}$ at room temperature was rapidly deposited on the window of an IR cell, maintained at $10 \mathrm{~K}$, the rate of Cope rearrangement of $\mathbf{1 b}$ to $\mathbf{2 b}$ could be measured by monitoring the rate of disappearance of $\mathbf{1 b}$, as the equilibrium mixture of 5260:1 of $\mathbf{2 b}: \mathbf{1 b}$ was established at cryogenic temperatures. ${ }^{29}$

This experiment could actually be performed on an equilibrium mixture of semibullvalene-2- $d_{1}$ and $4-d_{1}$ since at $10 \mathrm{~K}$ the former isotopomer is predicted to dominate the latter by a ratio of 74:1. Askani has, in fact, reported the synthesis of 1,5-dimethylsemibullvalene-2(4)- $d_{1} \cdot{ }^{30}$ Using this derivative of $\mathbf{1}$, an experimental test of our prediction that tunneling should allow semibullvalene to undergo rapid Cope rearrangement at cryogenic temperatures could be attempted. ${ }^{31}$

Acknowledgment. We thank the National Science and Robert A. Welch Foundations for support of this research. Helpful discussions with Professors Barry K. Carpenter (Cardiff University), Daniel A. Singleton (Texas A\&M University), and Richard V. Williams (University of Idaho) are gratefully acknowledged.

Supporting Information Available: The optimized B3LYP/6-31(d) geometries and energies for $\mathbf{1}$ and 3, the transition structures for their degenerate Cope rearrangements, and the TST and TST + SCT rate constants for this reaction. This material is available free of charge via the Internet at http://pubs.acs.org.

OL100879T 